\title{
Changes in Frequency of Use and Satisfaction of Visitors on Urban Forest as Recreational Resources \\ - Focused on Seonhaksan and Bibongsan Mountains, Jinju City, Korea -
}

\author{
Hyun-Cheol Heo ${ }^{1,2}$, Inhea Kim ${ }^{3}$, Keun Young Huh ${ }^{2,3,4}$, and Jong-Hoon Park \\ ${ }^{1}$ Greenery Park Division, Jinju City Hall, Jinju 52789, South Korea \\ ${ }^{2}$ Dept. of Urban System Engineering, Gyeongnam National University of Science and Technology, Jinju 52725, South Korea \\ ${ }^{3}$ International Garden Institute, Gyeongnam National University of Science and Technology, Jinju 52725, South Korea \\ ${ }^{4}$ Dept. of Landscape Architecture, Gyeongnam National University of Science and Technology, Jinju 52725, South Korea \\ ${ }^{5}$ School of Planning, Design and Construction, Michigan State University, Michigan 48824, USA
}

\begin{abstract}
This study was conducted to investigate the changes in the frequency of use, users' behaviour and satisfaction of Seonhaksan and Bibongsan mountains near city center improved through the park and green spaces projects implemented by Jinju City Hall from 2004 to 2016. The number of visitors per day was measured by observation surveys in 2004 and 2016. The users' behaviour and satisfaction were measured by questionnaires in 2004 and 2017. The collected data were analyzed by frequency analysis and independent sample t-test. The number of visitors per day increased about two times on weekdays and more than 2.5 times on weekends in 2016 than in 2004. Relatively the number of male visitors increased more than that of female visitors. The share of elderly visitors has increased and the number of visitors who live out of $1 \mathrm{~km}$ radius has increased. The goals of visit were changed from hiking or walking to various recreational activities, and the number of users visiting by car increased. The number of visits and the duration of visit has decreased. The inconveniences of trails and exercise facilities were significantly reduced, and the necessity of family recreational facilities fulfilled. The necessity of outdoor learning facilities and programs has not been recognized. Comprehensively, the results indicate that the recreational quality of Seonhaksan and Bibongsan mountains has improved. Further implementation of target-oriented parks and green spaces will be necessary in the future.
\end{abstract}

Keywords: inconvenience, necessity, observation survey, questionnaire, users behaviour

\section{Introduction}

Interest in the quality of life, wellbeing, healing, etc. has continued to grow, and combined with the improved economy and standard of living, the five-day work week that has been implemented by stages from July, 2004 has increased leisure time. The number of people who spend their leisure time doing recreational activities such as those for health, rest and amusement is ever increasing, and the demand for places, facilities, and programs for the activities is also increasing. To meet the growing demand from citizens, local autonomous governments have been planning and executing policies and

This work was supported by Gyeongnam National University of Science and Technology Grant in 2017.

Received: September 1, 2017, Revised: September 12, 2017, Accepted: September 14, 2017

*Comesponding author: sumoto@gntech.ac.kr 
projects to expand and improve spaces for recreational activities. Mountain areas in cities, easily accessible for people living in cities, provide plenty of natural resources, compared to urban parks, and meet the demand from those who want to experience the nature more frequently and have needs for healthier life. They also provide connectivity with other landscape elements as a key element of urban landscape (Shin et al., 2010).

Seonhaksan and Bibongsan, mountains located in the center of Jinju City, Gyeongnam, Korea, have been used as spaces for various recreational activities including light hiking. However, such areas have been relatively often excluded from projects for parks and green spaces due to their lower accessibility, and limitations to the development of mostly privately-owned lands. Jinju City had created small-scale exercise areas in Seonhaksan and Bibongsan mountains by 2004, and continues to add and improve new facilities for sports and recreation, and to built stairs in the existing hiking trails. The efforts have shown some positive results. Many countries in Europe have also utilized urban forests as a forest for recreation for citizens to experience the nature and take a rest, such as Grünwald in Munich, Bavaria, Germany, Wienerwald in Vienna, Austria, and Sihlwald in Zurich, Swiss (Lee et al., 2008). It is necessary to improve Seonhaksan and Bibongsan as urban forests that can meet the needs of citizens for recreational activities for health, rest and amusement.

Earlier studies on urban forests can be divided into three groups: first, those on the creation and preservation of urban forests, second, those on the benefits of urban forests, and third, those on the use of urban forests (Shin et al., 2010). Park (1991) measured the satisfaction level of users on Daesin Natural Park in Busan and analyzed the cause-and-effect relationship of recreational activities, and Kim and Huh (1992) conducted surveys on the behavioral characteristics of the users of 5 forests in Jeonju, and the satisfaction level of the users on the maintenance status. In regard of urban forests in Jinju, Gyeongnam, Heo et al. (2015) surveyed the recognition of citizens on the restoration and use of the damaged forest of Bibongsan, and Heo et al. (2016) analyzed the recognition and preference of local residents on plans for natural forests for recreation in suburb areas focusing on the plan for Worasan.

This study was conducted to analyze the behaviors and satisfaction level of users on urban forests in Jinju, Gyeongnam, in line with studies on the improvement of urban forests to fulfill the needs of citizens for recreation. To do so, this study selected Seonhaksan and Bibongsan, mountains located in the center of Jinju City, Gyeongnam, as a subject, and analyzed changes in the frequency of use, the behaviors and satisfaction of users on projects for parks and green spaces implemented by local autonomous governments from 2004 to 2016.

\section{Methods}

\section{Status of subjects}

Seonhaksan and Bibongsan are mountains located in the center of Jinju City, Gyeongnam as shown in Fig. 1. The height of Seonhaksan is $135.5 \mathrm{~m}$, and the total forest area is $2,374,147 \mathrm{~m}^{2}$. The area designated as a park is $1,140,000 \mathrm{~m}^{2}$, and the ratio of the designated area to the total forest area is $48 \%$. The slope of the west side sharply declines to the Nam River, and that of the north side is connected to Bonglaesan. Seonhaksan is located in the center of Jinju and easily accessible. Most of the hiking trails have a gentle slope (less than 5\%), and the view at the peak is good. It is the most visited mountain in Jinju, and the quality of hiking trails and exercises facilities is good. The height of Bibongsan is $138 \mathrm{~m}$, and the total forest area is $4,162,740 \mathrm{~m}^{2}$. The area designated as a park is $2,084,000 \mathrm{~m}^{2}$, and the ratio of the designated area to the total forest area is $50 \%$. Entrances to hiking trails on the south and west sides of the mountain have steep slopes. Since the length of the trails is short, it only takes 10 20 minutes to climb the ridges. Topographically, the slopes of the north and south sides to downtown are steep but the ridges have a gentle slope. Small-scale exercise areas are created at every 


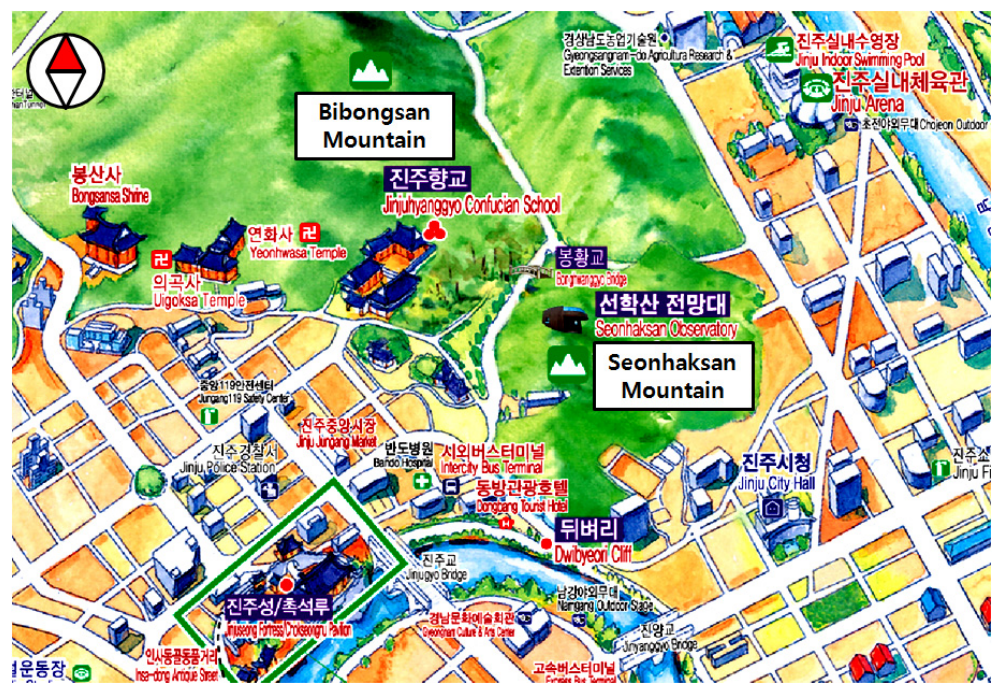

Figure 1. Panoramic view illustration of Seonhaksan and Bibongsan mountains in Jinju city center: The image was obtained and edited from the official tourism map of Jinju City Hall (Jinju City Hall, 2017).

point where access roads and hiking trails meet, and a large-scale exercise area is created at the peak of the mountain, and used by many citizens.

The basic directions of the policies of Jinju City on parks and green spaces are to actively preserve the Nam River that crosses the center of Jinju, and its branches, to add and maintain small-scale parks for daily use, to create a biotop network that connects the Nam River and mountain areas, and thus to create an open space system that links water spaces, parks, public facilities, residential areas and street networks. To achieve the goals, the government focuses on increasing the convenience of use by actively developing the already-designated parks rather than designating new forests. Key projects that had been executed from 2004 to 2016 to develop parks and green spaces in 7 mountains in Jinju, as shown in Table 1, were concentrated in Seonhaksan and Bibongsan. They were planned and executed through public contests, and approximately 9.5 billion won, $52 \%$ of the total budget, was spent to compensate for obstacles such as graves, and buy privately-owned lands.

\section{Observation, surveys and analysis}

To examine the frequency of use, key hiking trails in Seonhaksan and Bibongsan mountains were reviewed, and one point of location was selected for each mountain. The number of users were counted every two hours between $6 \mathrm{am}$ to $8 \mathrm{pm}$ for 2 days during weekdays and weekends respectively in summer from 2004 to 2016, and the arithmetic mean values of the collected data were calculated. The distribution of daily users during weekdays and weekends was examined, and changes during the period from 2004 and 2016 were also analyzed.

An on-site questionnaire survey was conducted in Seonhaksan and Bibongsan in summer from 2004 to 2017. To analyze the behaviors and recognition of users, the questionnaire was composed, as shown in Table 2, of 3 questions on the socio-demographic characteristics of respondents; 9 questions on the behaviors of use; 12 questions on inconveniences of hiking trails and exercise facilities; 6 questions on the necessity of outdoor learning facilities and programs; and 4 questions on the necessity of facilities for family recreational activities (Park, 1991; Kim and Huh, 1992; Lee and Kim, 2001; Park et al., 2002). The questions on the socio-demographic characteristics were divided into gender, age, and the distance between their residence and the entrance of the hiking trail, and every question was structured using a nominal 
Table 1. Projects implemented at Seonhaksan and Bibongsan mountains, Jinju city, Korea.

\begin{tabular}{|c|c|c|}
\hline Year & Project & $\begin{array}{l}\text { Budget } \\
\text { (million KRW) }\end{array}$ \\
\hline \multirow{8}{*}{2016} & $\begin{array}{l}\text { Improvement of urban forest in Seonhaksan mountain: making a rhododendron garden surrounding the } \\
\text { lookout of Seonhaksan mountain }\end{array}$ & 280 \\
\hline & $\begin{array}{l}\text { Compensation payment for demolishing obstacles (e.g., grave etc.) within urban forest park planning site } \\
\text { around the lookout of Seonhaksan mountain }\end{array}$ & 400 \\
\hline & $\begin{array}{l}\text { Compensation payment for purchasing privately owned lands and demolishing obstacles (e.g., grave etc.) } \\
\text { within urban forest planning site in Bibongsan mountain }\end{array}$ & 5,400 \\
\hline & Construction of forest park on Bibongsan mountain & 1,800 \\
\hline & Forest restoration & 167 \\
\hline & $\begin{array}{l}\text { Construction of Bonghwang Forest Eco Park in Bibongsan mountain (including the budget ( } 2.5 \text { billion KRW) } \\
\text { for purchasing privately owned lands within the site) }\end{array}$ & 4,100 \\
\hline & Construction of ecological trail in Bibongsan mountain & 200 \\
\hline & (Subtotal, 2016) & 12,347 \\
\hline \multirow[t]{3}{*}{2015} & Construction of urban forest & 200 \\
\hline & $\begin{array}{l}\text { Compensation payment for demolishing obstacles (e.g., grave etc.) within urban forest park planning site } \\
\text { around the lookout of Seonhaksan mountain }\end{array}$ & 400 \\
\hline & (Subtotal, 2015) & 600 \\
\hline \multirow[t]{5}{*}{2014} & Construction of urban forest & 200 \\
\hline & Construction and maintenance of forest resting place near Jinju city & 250 \\
\hline & Construction of a deck in Seonhaksan mountain & 50 \\
\hline & $\begin{array}{l}\text { Compensation payment for purchasing privately owned lands and demolishing obstacles (e.g., grave etc.) } \\
\text { within urban forest planning site in Seonhaksan mountain }\end{array}$ & 500 \\
\hline & (Subtotal, 2014) & 1,000 \\
\hline \multirow[t]{6}{*}{2013} & Purchasing privately owned lands within urban parks in preparation for disaster & 255 \\
\hline & Construction of urban forest & 200 \\
\hline & Installation of a toilet within forest park & 200 \\
\hline & Installation of security lights on the trails in Seonhaksan mountain & 100 \\
\hline & Establishment of foot bridge between Seonhaksan and Bibongsan mountains & 600 \\
\hline & (Subtotal, 2013) & 1,355 \\
\hline \multirow[t]{5}{*}{2012} & Forest enhancement of Bibongsan, Bongraesan, and Seonhaksan mountains & 2,000 \\
\hline & Installation of convenient facilities in Bibongsan mountain and improvement of the surrounding area & 100 \\
\hline & design contest and detailed design project for a lookout construction on Seonhaksan mountain & 200 \\
\hline & Construction of a lookout on Seonhaksan mountain & 1,600 \\
\hline & (Subtotal, 2012) & 3,900 \\
\hline \multirow[t]{5}{*}{2011} & Construction Planning project of a public park in Bibongsan mountain & 300 \\
\hline & Installation of lookout gazebo in Seonhaksan mountain & 100 \\
\hline & Construction of forest bath in Bibongsan mountain & 400 \\
\hline & Installation of exercise facilities in Bibongsan mountain & 40 \\
\hline & (Subtotal, 2011) & 840 \\
\hline \multirow{2}{*}{2010} & Maintenance of forest trail deck & 250 \\
\hline & (Subtotal, 2010) & 250 \\
\hline \multirow[t]{3}{*}{2008} & $\begin{array}{l}\text { Expansion of exercise and convenience facilities in } 7 \text { mountains including Seonhaksan and Bibongsan } \\
\text { mountain }\end{array}$ & 45 \\
\hline & (Subtotal, 2008) & 45 \\
\hline & Total & $\mathbf{1 8 , 0 3 7}$ \\
\hline
\end{tabular}


Table 2. Scheme of questionnaire design.

\begin{tabular}{|c|c|c|}
\hline Category & Variable & No. of questions \\
\hline $\begin{array}{l}\text { Socio-demographic } \\
\text { background }\end{array}$ & Gender; age; distance between the residence and the entrance & 3 \\
\hline Users' behavior & Goals of visit; means of transportation; time of visits; duration of visit & 9 \\
\hline $\begin{array}{l}\text { Inconvenience of trails } \\
\text { and exercise facilities }\end{array}$ & $\begin{array}{l}\text { The trails are narrow; there are too many forked trails; the trail surface is not good; } \\
\text { nearby forest maintenance is needed; improvement of surrounding facilities and signs } \\
\text { is needed; I feel inconvenient to use the trails; the exercise ground is too small; the } \\
\text { surface of the exercise ground is uncomfortable (slippery, rugged etc.); there are too } \\
\text { few kinds of exercise facilities; the exercise facilities are worn out; improvement of } \\
\text { facilities is needed (sound, lighting etc.); I feel inconvenient using the exercise } \\
\text { grounds or related facilities }\end{array}$ & 12 \\
\hline $\begin{array}{l}\text { Necessity of outdoor } \\
\text { learning facilities and } \\
\text { programs }\end{array}$ & $\begin{array}{l}\text { Information of forest and trees, such as tree name tags and signs, is required; } \\
\text { information of natural resources such as insects, birds, and animals is needed; it is } \\
\text { necessary to create separate educational places such as gardens; it is necessary to } \\
\text { create educational facilities such as forest classrooms; forest programs such as forest } \\
\text { library operation are needed; proper spaces for outdoor learning are needed }\end{array}$ & 6 \\
\hline $\begin{array}{l}\text { Necessity of family } \\
\text { recreational activity } \\
\text { facilities }\end{array}$ & $\begin{array}{l}\text { Resting facilities are needed such as forest bath seats and decks; a place to rest quietly } \\
\text { is needed; a little rest space for the family is needed; it is necessary to create some } \\
\text { spaces for recreation such as forest baths }\end{array}$ & 4 \\
\hline
\end{tabular}

scale. In regard of the behaviors of use, the question on the goals of visit were structured with answers including hiking or walking trails; physical activity related to hobby; outdoor learning; and forest bathing and recreation with family, and it was assessed using a 5-point likert scale. The question on the means of transportation was structured with answers including walking, bicycling, and driving, and it was assessed using a 5-point likert scale. The number of visits and the duration of visit were structured using a nominal scale (Kim and Huh, 2004). Respondents were instructed to circle a number from 1 (highly agree) to 5 (highly disagree) in questions assessed using a 5-point likert scale, and in the process of statistical analysis, 1 was converted into 5, and 5 into 1 (Kim and Huh, 2004; Kim et al., 2009; Kim and Huh, 2016). All the questions on the inconveniences of trails and exercise facilities, the necessity of outdoor learning facilities and programs, and the necessity of family recreational facilities were structured using a 5-point likert scale.

Researchers briefly explained the purpose and methods of this survey to those who agreed to participate in the on-site survey, and they were instructed to answer to the personal self-administration questionnaire. Among the collected questionnaires, a total of 150 questionnaires that were answered sufficiently were statistically analyzed. Frequency analysis was conducted on the questions structured using a nominal scale using IBM SPSS Statistics ver. 24, and the independent samples t-test was conducted on the questions structured using a 5-point likert scale in order to analyze changes during the period from 2004 and 2016.

\section{Results and Discussion}

The number of daily users of Seonhaksan was 244 during weekdays and 159 during weekends in 2004, and 463 during weekdays and 408 during weekends in 2016, and the number in 2016 increased by 1.9 times during weekdays, and by 2.6 times during weekends compared to 2004 (Fig. 2). In terms of the gender of the daily users of Seonhaksan, males and females accounted for $43 \%$ and $57 \%$ respectively during weekdays in 2004 , and $52 \%$ and $48 \%$ respectively during weekends. In 2016, males and females accounted for $46 \%$ and $54 \%$ respectively during weekdays, and $49 \%$ and $51 \%$ 


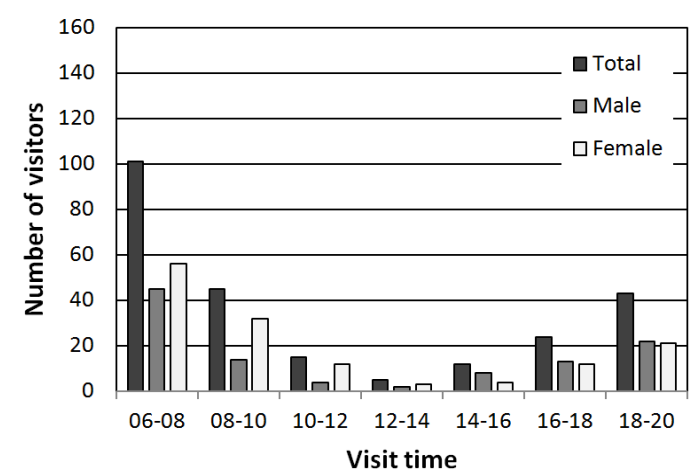

(a) Weekday in 2004

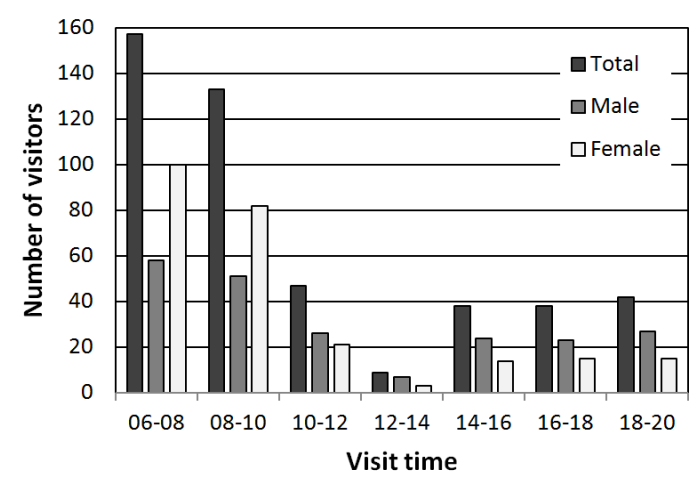

(c) Weekday in 2016

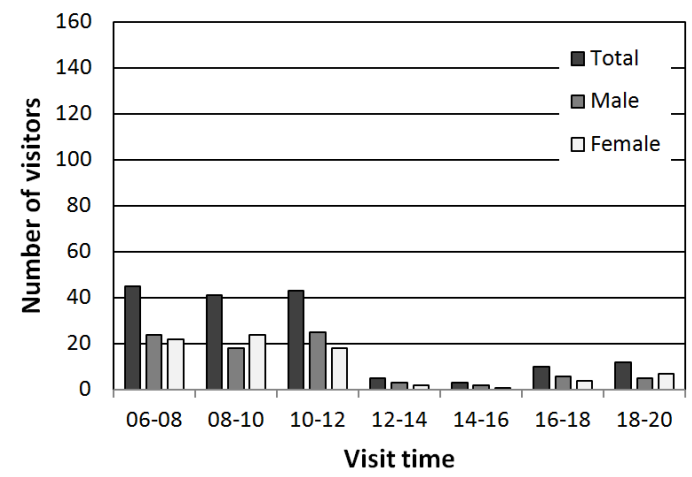

(b) Weekend in 2004

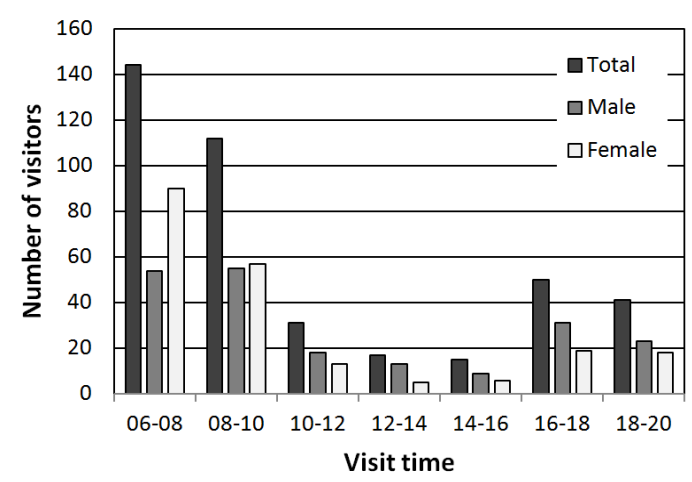

(d) Weekend in 2016

Figure 2. The number of visitors per day to Seonhaksan mountain in 2004 and 2016 at the same among entrances.

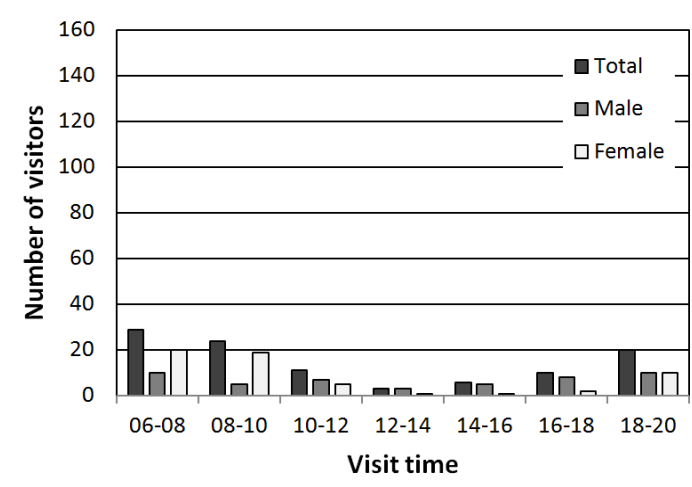

(a) Weekday in 2004

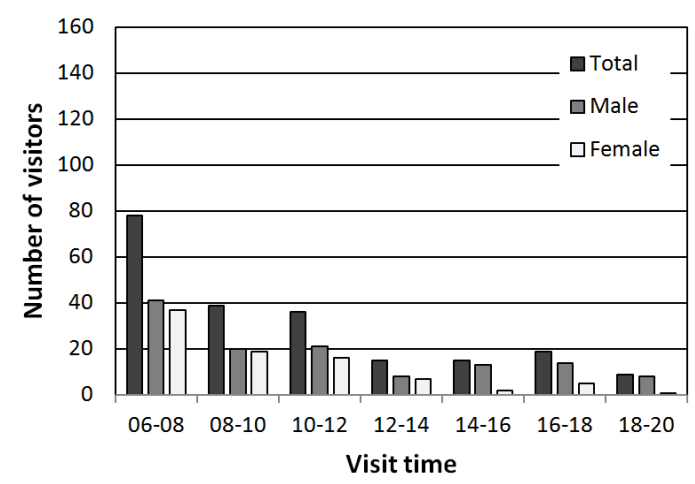

(c) Weekday in 2016

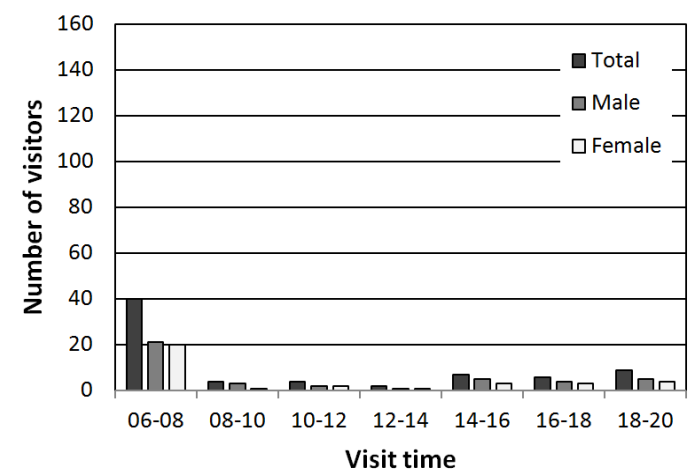

(b) Weekend in 2004

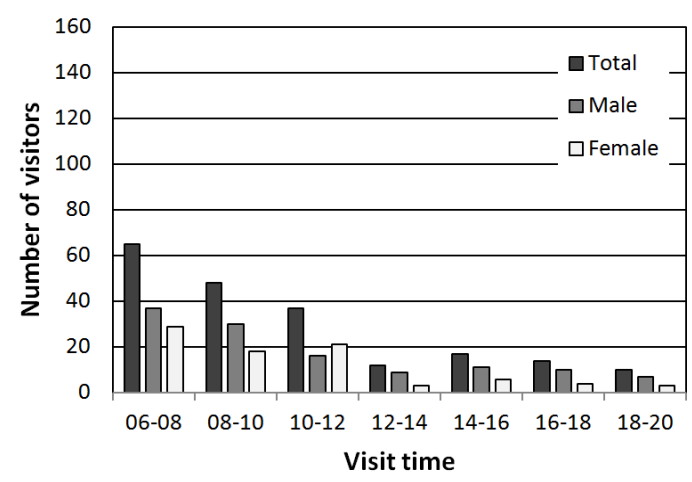

(d) Weekend in 2016

Figure 3. The number of visitors per day to Bibongsan mountain in 2004 and 2016 at the same among entrances. 
respectively during weekends. The percentage of males during weekdays in 2016 increased by $3 \%$ compared to that in 2004 , and the percentage of females during weekends in 2016 increased by $3 \%$ compared to that in 2004 . The number of daily users of Bibongsan was 102 during weekdays and 71 during weekends in 2004, and 210 during weekdays and 201 during weekends in 2016, and the number in 2016 increased by 2.1 times during weekdays, and by 2.8 times during weekends compared to the number in 2004 (Fig. 3). In terms of the gender of the daily users of Bibongsan, males and females accounted for $46 \%$ and $54 \%$ respectively during weekdays, and $55 \%$ and $45 \%$ during weekends in 2004, and 59\% and $41 \%$ respectively during weekends, and $59 \%$ and $41 \%$ during weekends in 2016 . The percentage of males during weekdays in 2016 increased by 13\% compared to that in 2004, and the percentage of males during weekends in 2016 increased by $4 \%$ compared to that in 2004 . The results indicate that the five-day work week and the shortened work hours (Yi and Kim, 2015), or the improved quality of recreation in Seonhaksan and Bibongsan increased the total number of visitors during weekdays in 2016 by about 2 times compared to that in 2004, and by 2.5 times during weekends. The number of males increased more than that of females.

The distribution of daily users both in 2004 and 2016, regardless of weekdays or weekends, was high between 6am and 10am. The distribution of daily users in 2004 showed some difference between weekdays and weekends, but that in 2016 did not show any significant difference between weekdays and weekends. The results indicate that the behaviors of users during weekdays and weekends in 2016 were relatively similar or identical, compared to those in 2004 . The percentage of females was higher in the morning both in 2004 and 2016, and that of males was higher in the afternoon, which is attributable to the housekeeping activity of females or safety issues at night.

In terms of the gender of the respondents, males accounted for $60.7 \%$ in 2004, and 37.2\% in 2017 (Table 3). The results are not coincident with those of the observation survey on the distribution of daily users shown in Fig. 1 and 2. The results of a study on urban parks in Busan (Park, 1991) showed that males accounted for approximately $49.0 \%$, and the share of males in a study on natural recreational forests and urban forests in Gyeongnam areas (Lee, 2012) was 47\%, and that of studies of Heo et al. (2016) and Kim and Huh (2016) was about 60\%. These results indicate that the closer the recreational

Table 3. Socio-demographic background.

\begin{tabular}{|c|c|c|c|c|c|}
\hline & & \multicolumn{2}{|c|}{2004} & \multicolumn{2}{|c|}{2017} \\
\hline & & Frequency & $\begin{array}{l}\text { Valid percent } \\
\qquad(\%)\end{array}$ & Frequency & $\begin{array}{l}\text { Valid percent } \\
(\%)\end{array}$ \\
\hline \multirow{2}{*}{ Gender } & Male & 91 & 60.7 & 54 & 37.2 \\
\hline & Female & 56 & 37.3 & 91 & 62.8 \\
\hline \multirow{5}{*}{$\begin{array}{l}\text { Age } \\
\text { (years old) }\end{array}$} & Under 20 & 4 & 2.7 & 3 & 2.0 \\
\hline & $21-30$ & 14 & 9.3 & 7 & 4.7 \\
\hline & $31-40$ & 25 & 16.7 & 8 & 5.4 \\
\hline & $41-60$ & 62 & 41.3 & 60 & 40.5 \\
\hline & Over 60 & 45 & 30.0 & 70 & 47.3 \\
\hline \multirow{5}{*}{$\begin{array}{l}\text { Distance between the residence } \\
\text { and the entrance }(\mathrm{m})\end{array}$} & Within 100 & 6 & 4.0 & 4 & 2.7 \\
\hline & $100-300$ & 19 & 12.8 & 9 & 6.1 \\
\hline & $300-500$ & 24 & 16.1 & 11 & 7.4 \\
\hline & $500-1000$ & 54 & 36.2 & 40 & 27.0 \\
\hline & Over 1000 & 46 & 30.9 & 84 & 56.8 \\
\hline
\end{tabular}


spaces are to the center of cities, and the more accessible they are, the number of female visitors or respondents increases.

The share of the respondents aged between 41 and 60 in 2004 was $41.3 \%$, and that of those aged over $60,30.0 \%$. That of those aged between 41 and 60 in 2017 was $40.5 \%$, and that of those aged over 60, 47.3\%. Earlier studies conducted on national parks and natural recreational forests (Cho, 2007; Cho, 2012; Lee, 2012) found that the share of respondents in their 30s and 50s was high, and the results of a study on urban forests (Heo et al., 2016) showed that the share of those in their 20s was high. Compared to these results, the share of elderly respondents in this study was relatively high in 2004, and that of elderly respondents increased more in 2017. These results are attributable to the fact that Seonhaksan and Bibongsan are located in the center of city unlike national parks and natural recreational forests, which makes elderly users visit in a relatively convenient way, and, in the mean time, they can be also attributable to the aging population in Jinju.

The share of the respondents who answered that the distance between their residence and the entrance of the entrance of the hiking trail is less than $1,000 \mathrm{~m}$ was $69.1 \%$ in 2004 , and $43.2 \%$ in 2017 , which indicates that the share of visitors who live $1 \mathrm{~km}$ or further away from the mountains in 2017 increased compared to that in 2004 . These results indicate that the accessibility to and the quality of recreational activities in Seonhaksan and Bibongsan have been improved by the projects for parks and green spaces listed in Table 1.

The mean value of hiking and walking trails among the goals of visits decreased from 4.50 in 2004 to 4.03 in 2017, showing a statistically significant difference. There was no statistically significant difference in the share of physical activity related to hobby between 2004 and 2017, but that of outdoor learning, and forest bathing and recreation with family increased from 2.08 to 2.65 , and from 2.95 to 3.30 respectively, showing a statistically significant difference (Table 4). Although the mean value of outdoor learning was lower than 3.00, and that of forest bathing and recreation with family, slightly higher than 3.00, the results still indicate that the environment for the two types of goals in Seonhaksan and Bibongsan was improved, or that the interest and needs of visitors increased. In overall, the goals of visits have shifted from routine activities such as hiking or walking trails to various recreational activities.

In terms of the means of transportation, the mean value of walking decreased from 4.55 in 2004 to 3.79 to 2017, showing a statistically significant difference, and that of bicycling and driving increased from 1.52 in 2004 to 2.53 in 2017, and from 1.57 to 3.04 respectively, showing a statistically significant difference (Table 4). As shown in Table 3 , the number of visitors from remote places in 2017 increased compared to that in 2004, and the accessibility to the mountains

Table 4. Goals of visit and means of transportation to Seonhaksan and Bibongsan mountains in 2004 and 2017.

\begin{tabular}{|c|c|c|c|c|c|c|}
\hline & & \multicolumn{2}{|c|}{2004} & \multicolumn{2}{|c|}{2017} & \multirow{2}{*}{$\frac{\text { t-test }}{\text { Sig. (2-tailed) }}$} \\
\hline & & Mean & $\begin{array}{l}\text { Std. Error } \\
\text { Mean }\end{array}$ & Mean & $\begin{array}{l}\text { Std. Error } \\
\text { Mean }\end{array}$ & \\
\hline \multirow{4}{*}{ Goals of visits } & Hiking or walking trails & 4.50 & .06 & 4.03 & .07 & $.000^{* *}$ \\
\hline & Physical activity related to my hobby & 2.67 & .11 & 2.63 & .08 & $.765^{\mathrm{NS}}$ \\
\hline & Outdoor learning & 2.08 & .09 & 2.65 & .08 & $.000^{* *}$ \\
\hline & Forest bathing and recreation with family & 2.95 & .11 & 3.30 & .09 & $.010^{*}$ \\
\hline \multirow{3}{*}{$\begin{array}{l}\text { Means of } \\
\text { transportation }\end{array}$} & Walking & 4.55 & .06 & 3.79 & .09 & $.000^{* *}$ \\
\hline & Bicycling & 1.52 & .08 & 2.53 & .09 & $.000^{* *}$ \\
\hline & Driving & 1.57 & .08 & 3.04 & .11 & $.000^{* *}$ \\
\hline
\end{tabular}

${ }^{\mathrm{NS}}$ non significance, ${ }^{*} p<.05,{ }^{* *} p<.01$. 
was increased by improving facilities such as parking lots and bicycle racks.

In terms of the number of visits, the share of "everyday" was highest (62.4\%) in 2004, and that of " 2 or 3 times a week" was highest $31.5 \%$ in 2017 (Table 5). In terms of the duration of visit, the share of "1-2 hours" was highest both in 2004 (49.3\%) and 2017 (44.0\%) (Table 5). The number of visits and the duration of visit in 2017 were relatively lower than those in 2004, which shows changes in the behaviors of users such as the increasing number of visitors from remote places (Table 3), and the diversified goals of visits (Table 4).

In terms of inconveniences of trails and exercise facilities, the mean value of "the trail is narrow," "nearby forest maintenance is needed," and "improvement of surrounding facilities and signs is needed" decreased statistically significantly in 2017, compared to 2004, which indicates that the level of inconveniences has been relatively reduced (Table 6). The answer of "I feel inconvenient to use the trails" decreased from 2.99 in 2004 to 2.77 in 2017, but did not show a statistically significant difference. The mean value is less than 3.00 , which can be interpreted that visitors do not feel inconvenient to use trails. The answers such as "the exercise ground is too small," "the surface of the exercise ground is uncomfortable (slippery, rugged, etc.)," "there are too few kinds of exercise facilities," "the exercise facilities are worn out," "improvement of facilities is needed (sound, lighting, etc.)," and "I feel inconvenient to use the exercise ground or related facilities," showed a statistically significant decrease in 2017, compared to 2004, which indicates that the inconveniences of exercise facilities have been reduced. However, the mean value of the answers, but for "the surface of the exercise ground is uncomfortable (slippery, rugged, etc.),"and "I feel inconvenient to use the exercise ground or related facilities," was still higher than 3.00, which means that visitors still felt inconvenient. These results indicate that the projects for parks and green spaces listed in Table 1 reduced inconveniences of hiking trails and exercise facilities in Seonhaksan and Bibongsan mountains. However, the mean value of most of the answers was still higher than 3.00, and thus it is necessary to execute additional and target-oriented projects for parks and green spaces focusing on hiking trails and exercise facilities.

In terms of the necessity of outdoor learning facilities and programs, the mean value of "information of forest and trees,

Table 5. Number of visits and duration of visit to Seonhaksan and Bibongsan mountains in 2004 and 2017.

\begin{tabular}{|c|c|c|c|c|c|}
\hline & & \multicolumn{2}{|c|}{2004} & \multicolumn{2}{|c|}{2017} \\
\hline & & Frequency & Valid percent (\%) & Frequency & Valid percent $(\%)$ \\
\hline \multirow{6}{*}{ Number of visits } & Once a month & 6 & 4.0 & 35 & 23.5 \\
\hline & 2 or 3 times a week & 31 & 20.8 & 47 & 31.5 \\
\hline & Once a week & 11 & 7.4 & 32 & 21.5 \\
\hline & Everyday & 93 & 62.4 & 24 & 16.1 \\
\hline & More than twice a day & 8 & 5.4 & 11 & 7.4 \\
\hline & Total & 141 & 100.0 & 138 & 100.0 \\
\hline \multirow{6}{*}{ Duration of visit } & $10 \mathrm{~min}$. & 1 & .7 & 5 & 3.3 \\
\hline & $30 \mathrm{~min}$. & 8 & 5.3 & 10 & 6.7 \\
\hline & One hour & 38 & 25.3 & 49 & 32.7 \\
\hline & $1-2$ hours & 74 & 49.3 & 66 & 44.0 \\
\hline & 2-4 hours & 29 & 19.3 & 20 & 13.3 \\
\hline & Total & 262 & 100.0 & 268 & 100.0 \\
\hline
\end{tabular}


such as tree name tags and signs, is required," "information of natural resources such as insects, birds, and animals is needed," "it is necessary to create separate educational places such as gardens," "it is necessary to create educational facilities such as forest classroom," "forest programs such as forest library operation are needed," and "proper spaces for outdoor learning are needed" did not show any statistically significant difference between 2004 and 2017 (Table 7). As earlier studies of Park et al. (2002), Connell and Meyer (2004), Ballantyne et al. (2008), Kim et al. (2010), and Park et al. (2013) found that the share of learning out of the goals of visits to natural recreational forests and botanical gardens was very low, the mean value of outdoor learning in this study was also lower than 3.0 both in 2004 and 2017 (Table 4). The results show that the interest and needs of elderly people, taking up the majority of visitors (Table 3 ), for outdoor learning are relatively low, and that there has been no significant change in their recognition. They are also attributable to the fact

Table 6. Inconvenience of trails and exercise facilities on Seonhaksan and Bibongsan mountains in 2004 and 2017.

\begin{tabular}{|c|c|c|c|c|c|}
\hline & \multicolumn{2}{|c|}{2004} & \multicolumn{2}{|c|}{2017} & \multirow{2}{*}{$\frac{\text { t-test }}{\text { Sig. }}$} \\
\hline & Mean & $\begin{array}{l}\text { Std. Error } \\
\text { Mean }\end{array}$ & Mean & $\begin{array}{l}\text { Std. Error } \\
\text { Mean }\end{array}$ & \\
\hline The trails are narrow & 3.31 & .09 & 2.90 & .07 & $.000^{* *}$ \\
\hline There are too many forked trails & 3.07 & .10 & 3.16 & .08 & $.503^{\mathrm{NS}}$ \\
\hline The trail surface is not good & 3.25 & .10 & 3.15 & .07 & $.416^{\mathrm{NS}}$ \\
\hline Nearby forest maintenance is needed & 3.49 & .10 & 3.16 & .07 & $.008^{* *}$ \\
\hline Improvement of surrounding facilities and signs is needed & 3.71 & .09 & 3.24 & .08 & $.000^{* *}$ \\
\hline I feel inconvenient to use the trails & 2.99 & .09 & 2.77 & .07 & $.065^{\mathrm{NS}}$ \\
\hline The exercise ground is too small & 3.30 & .09 & 3.01 & .07 & $.013^{*}$ \\
\hline The surface of the exercise ground is uncomfortable (slippery, rugged etc.) & 3.08 & .08 & 2.86 & .07 & $.049^{*}$ \\
\hline There are too few kinds of exercise facilities & 3.46 & .09 & 3.05 & .07 & $.000^{* *}$ \\
\hline The exercise facilities are worn out & 3.51 & .08 & 3.16 & .08 & $.002^{* *}$ \\
\hline Improvement of facilities is needed (sound, lighting etc.) & 3.33 & .09 & 3.01 & .08 & $.009^{* *}$ \\
\hline I feel inconvenient to use the exercise grounds or related facilities & 3.19 & .08 & 2.77 & .08 & $.000^{* *}$ \\
\hline
\end{tabular}

${ }_{\text {NS }}$ non significance, ${ }^{*} p<.05, \stackrel{* *}{p} p .01$.

Table 7. Necessity of outdoor learning facilities and programs on Seonhaksan and Bibongsan mountains in 2004 and 2017.

\begin{tabular}{|c|c|c|c|c|c|}
\hline & \multicolumn{2}{|c|}{2004} & \multicolumn{2}{|c|}{2017} & \multirow{2}{*}{ 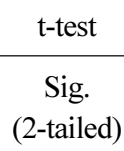 } \\
\hline & Mean & $\begin{array}{l}\text { Std. Error } \\
\text { Mean }\end{array}$ & Mean & $\begin{array}{l}\text { Std. Error } \\
\text { Mean }\end{array}$ & \\
\hline Information of forest and trees, such as tree name tags and signs, is required & 3.69 & .08 & 3.53 & .07 & $.132^{\mathrm{NS}}$ \\
\hline Information of natural resources such as insects, birds, and animals is needed & 3.29 & .09 & 3.41 & .07 & $.285^{\mathrm{NS}}$ \\
\hline It is necessary to create separate educational places such as gardens & 3.18 & .09 & 3.06 & .08 & $.325^{\mathrm{NS}}$ \\
\hline It is necessary to create educational facilities such as forest classrooms & 3.15 & .09 & 3.17 & .08 & $.868^{\mathrm{NS}}$ \\
\hline Forest programs such as forest library operation are needed & 3.16 & .10 & 3.13 & .09 & $.838^{\mathrm{NS}}$ \\
\hline Proper spaces for outdoor learning are needed & 3.21 & .09 & 3.23 & .07 & $.854^{\mathrm{NS}}$ \\
\hline
\end{tabular}

NS non significance. 
Table 8. Necessity of family recreational activity facilities on Seonhaksan and Bibongsan mountains in 2004 and 2017.

\begin{tabular}{|c|c|c|c|c|c|}
\hline & \multicolumn{2}{|c|}{2004} & \multicolumn{2}{|c|}{2017} & \multirow{2}{*}{$\begin{array}{c}\text { t-test } \\
\text { Sig. } \\
\text { (2-tailed) }\end{array}$} \\
\hline & Mean & $\begin{array}{c}\text { Std. Error } \\
\text { Mean }\end{array}$ & Mean & $\begin{array}{l}\text { Std. Error } \\
\text { Mean }\end{array}$ & \\
\hline Resting facilities are needed such as forest bath seats and decks & 3.95 & .08 & 3.59 & .08 & $.002^{* *}$ \\
\hline A place to rest quietly is needed & 3.70 & .09 & 3.48 & .08 & $.053^{\mathrm{NS}}$ \\
\hline A little rest space for the family is needed & 3.66 & .09 & 3.37 & .08 & $.014^{*}$ \\
\hline It is necessary to create some spaces for recreation such as forest baths & 3.81 & .08 & 3.54 & .08 & $.018^{*}$ \\
\hline
\end{tabular}

${ }^{\mathrm{NS}}$ non significance, ${ }^{*} p<.05,{ }^{* *} p<.01$.

that outdoor learning facilities and programs have been relatively less improved, or that their recognition on the necessity of such facilities and programs has not changed yet.

In terms of the necessity of family recreational facilities, the mean value of "resting facilities are needed such as forest bath seats and decks," "a little rest space for the family is needed," and "it is necessary to create some spaces for recreation such as forest bath," showed a statistically significant decrease in 2017, compared to 2004, and that of "a place to rest quietly is needed" tended to decrease (Table 8). The results show that family recreational facilities have been relatively improved, and thus that the needs for them have been fulfilled. In other words, as earlier studies of Lee and Kim (2001), Kim and Noh (2011), Lee (2012), Park et al. (2013), Heo et al. (2016) found that visitors tended to put a high priority on taking a rest with family out of the goals of visits to natural recreational forests, the mean value of forest bathing and recreation with family in this study was second highest (2.95 in 2014, 3.30 in 2017), after hiking and walking trails (Table 4). After the projects for parks and green spaces listed in Table 1 had been implemented to meet such a high interest in and needs for them, facilities for forest bathing and recreation with family in Seonhaksan and Bibongsan have been also improved.

\section{Conclusions}

Local autonomous governments have been implementing various projects for parks and green spaces to expand and improve spaces for recreational facilities. Urban forests are relatively easily accessible and have plenty of natural resources, providing pleasant recreational spaces. In this regard, this study, in line with studies on the improvement of urban forests, was conducted to analyze the frequency of use and the behaviors and satisfaction level of visitors to Seonhaksan and Bibongsan, mountains located in the center of Jinju City, Gyeongnam, from 2004 to 2016, and thus to examine the effects of the projects for parks and green spaces that had been implemented by Jinju City. The projects have been executed to develop parks and green spaces in 7 mountains in Jinju, and most were concentrated in Seonhaksan and Bibongsan. The planned budget for the projects was approximately 18 billion won, and around 9.5 billion won, $52 \%$ of the total budget, was spent to compensate for obstacles such as graves and to buy privately-owned lands. An observation survey was conducted to count the number of daily users from 2004 to 2017, and a questionnaire survey was conducted to examine the behaviors and satisfaction level of users from 2004 to 2017. The collected data were statistically analyzed using frequency analysis and the independent samples t-test. The total number of users in 2016 increased by 2 times during weekdays, and by over 2.5 times during weekends compared to that in 2004 . The number of male visitors increased more than that of female visitors. The share of elderly visitors relatively increased, and the number of visitors who live 
$1 \mathrm{~km}$ or further away from the mountains also increased. The goals of visits shifted from routine activities such as hiking or walking trails to various recreational activities, and the share of visitors who came to the mountains by driving increased. The number of visits and the duration of visit decreased. Inconveniences of hiking trails and exercise facilities showed a statistically significant decrease, and facilities for family recreational facilities were improved. However, the recognition on the necessity of outdoor learning facilities and programs did not increase.

Given the results of this study, it can be concluded that the projects for parks and green spaces that had been implemented by Jinju City by 2016 have improved the quality of recreation in Seonhaksan and Bibongsan, and, in detail, the satisfaction level of users has been significantly improved in 2017 compared to that in 2004. However, the level still remains at a normal level, and thus it will be necessary to execute additional target-oriented projects of parks and green spaces. Specifically speaking, it is necessary to develop plans to preserve natural resources and properly operate and manage facilities in order to meet the growing number of users and their needs. In addition, it is needed to develop measures to promote the use of females and people in younger age groups, and to expand convenient facilities for visitors who come from remote places. Plans to introduce various facilities and programs other than hiking and walking trails need to be developed by analyzing the needs of users for recreational facilities. In order to increase the number of visits and the duration of visit, it will be also necessary to develop and operate family recreational facilities, and outdoor learning facilities and programs.

\section{References}

Ballantyne, R., J. Packer, and K. Hughes. 2008. Environmental awareness, interests and motives of botanic gardens visitors: implications for interpretive practice. Tour. Manag. 29(3):439-444. DOI: 10.1016/j.tourman.2007.05.006

Cho, K.J. 2007. A study of visitor characteristics for development of interpretative program for the park: Case study of Woraksan national park. J. Korean Inst. For. Recreat. 11(2):1-9.

Cho, K.J. 2012. A study of visitor characteristics for development of forest interpretative program for the Bakun-san recreation forest: Case study of Baeunsan Recreation Foreat. J. Korean Inst. For. Recreat. 16(1):93-101.

Connell, J. and D. Meyer. 2004. Modelling the visitor experience in the gardens of Great Britain. Curr. Issues Tour. 7(3):183-216. DOI:10.1080/13683500408667979

Heo, H.C., K.Y. Huh, and J.H. Park. 2015. Civic consciousness analysis on the damaged forest lands' restoration and use: Focused on Bibongsan mountain, Jinju city, South Korea. J. Korean. Soc. People Plants Environ. 18(5):403-412. DOI: 10.11628/ksppe.2015.18.5.403

Heo, H.C., I. Kim, E.J. Jo, K.Y. Huh, and J.H. Park. 2016. Analysis on residents recognition and preference for planning a natural recreation forest near city: Focused on planning Mt. Wora natural recreation forest in Jinju city. J. Korean. Soc. People Plants Environ. 19(6):639-647. DOI: 10.11628/ksppe.2016.19.6.639

Jinju City Hall. 2017. Jinju tourism map. Retrieved from http://tour.jinju.go.kr/tour_map/sub/01_01.jsp?cate_sight=SIGHT001

Kim, B.S. and J.H. Noh. 2011. Analysis on visitors of recreation forest in and around the metropolitan area. J. Korean Inst. For. Recreat. 15(2):51-60.

Kim, B.S., J.H. Noh, and J.C. Park. 2010. A study on the users' attribute of National Recreation Forest in and around Seoul National Capital Area. J. Korean Inst. For. Recreat. 14(4):105-114.

Kim, I. and K.Y. Huh. 2004. Evaluating user's cognition and satisfaction in a hospital roofgarden environment: A case study of Asan medical center. J. Korean Soc. Plants People Environ. 7(2):62-73.

Kim, I., H.C. Heo, and K.Y. Huh. 2009. Evaluating user's behavior and satisfaction on pop-jet fountain of Namgaram park in Jinju. J. Korean Soc. People Plants Environ. 12(3):53-67.

Kim, J.M. and K.Y. Huh. 2016. Structure model analysis on visitors satisfaction of sightseeing in Mt. Keumwon arboretum. 
J. Korean Soc. People Plants Environ. 19(3):261-263. DOI: 10.11628/ksppe.2016.19.3.261

Kim, S.C. and J. Huh. 1992. A study on the users' behavior and satisfaction on the actual conditions of management at the neighborhood parks in Chonju. J. Korean Inst. Landsc. Archit. 20(2):90-105.

Lee, C.K. 2012. A study on the consciousness on forest protection and use patterns of visitor in Mt. Keumwon National Recreational Forest. J. Korean Inst. For. Recreat. 63(3):95-100.

Lee, J.L. and S.Y. Kim. 2001. A study on patterns in use of visitors to recreational forests near cities and their awareness of recreation culture in forest. J. Korean Inst. For. Recreat. 5(3):19-26.

Lee, Y.H., K.W. Kim, W.H. Byun, and Y.H. Yoon. 2008. A study on the use of urban forest in Europe: Based on the case of Switzerland, Austria and Cermany. Proc. J. Korean Inst. For. Recreat. p.36-41.

Park, B.H., S.K. Kim, S.M. Kim, S.B. Yoon, and M.J. Park. 2013. Studies for using type and benefits of the visitors in the natural recreation forest. J. Korean Inst. For. Recreat. 17(4):59-67.

Park, M.S., K.W. An, K.S. Jeon, and J.M. Park. 2002. The current usage of recreation forests under the Western National Forest office. J. Korean Inst. For. Recreat. 6(3):87-94.

Park, S.B. 1991. A study on the developmental direction with reference to user's satisfaction of urban park: Case study of Daeshin natural park in Pusan city. J. Korean Inst. Landsc. Archit. 19(3):87-97.

Shin, W.S., P.S. Yeoun, J.H. Lee, J.K. Lee, and K.M. Kim. 2010. The important-performance analysis of urban recreational forests. J. Korean Inst. For. Recreat. 14(1):17-29.

Yi, J. and S. Kim. 2015. The effects of reduction in legal working hours reconsidered. Econ. Soc. 108:108-136. 